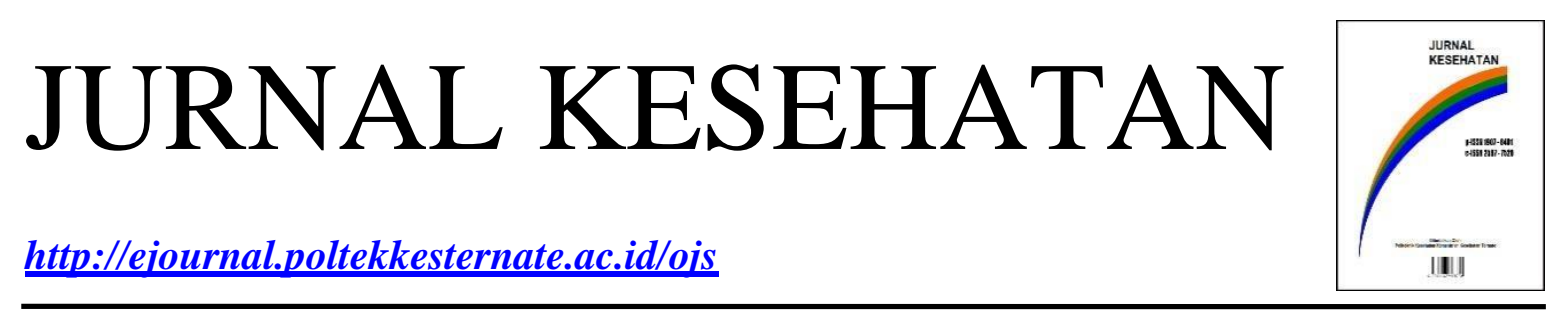

\title{
HUBUNGAN INDEKS MASSA TUBUH (IMT) DENGAN USIA MENARCHE PADA REMAJA PUTRI DI SMP MUHAMMADIYAH I KOTA TERNATE TAHUN 2018
}

\author{
Nurdiana Lante \\ ${ }^{1}$ Poltekkes Kemenkes Ternate, Indonesia \\ nurdiana lante@yahoo.co.id
}

\begin{tabular}{l} 
Info Artikel \\
\hline Sejarah Artikel: \\
Diterima 20 Juni 2019 \\
Disetujui 10 Juli 2019 \\
Di Publikasi 30 \\
November 2017
\end{tabular}

Keywords:

Indeks Massa Tubuh.

\begin{abstract}
Abstrak
Menarche atau menstruasi pertama merupakan salah satu dari banyak manifestasi pubertas dan tanda remaja awal pada perempuan. Pergeseran usia menarche ke usia yang lebih muda, akan menyebabkan remaja putri mengalami dampak stress emosional. Beberapa penelitian juga menyebutkan bahwa usia menarche di bawah 12 tahun berhubungan dengan risiko terkena kanker payudara, obesitas abdominal, resistensi insulin, penumpukan lemak dalam jaringan adiposa, risiko penyakit kardiovaskular dan hipertensi. Variasi saat timbulnya menarche dipengaruhi oleh berbagai faktor, salah satunya adalah Berat badan. Dalam penelitian ini berat badan di ukur menggunakan parameter Indeks Massa Tubuh (IMT). Tujuan penelitian ini adalah untuk mengetahui adanya hubungan IMT dengan usia Menarche.Jenis penelitian ini adalah analitik korelasi dengan desain studi cross sectional. Tekhnik sample yang digunakan adalah Total sampel sebanyak 34 siswi. Penelitian ini dilaksanakan pada bulan September sampai dengan November 2018 di SMP Muhammadiyah I Kota Ternate. Data penelitian diperoleh dengan wawancara dan pengukuran langsung terhadap Berat dan tinggi Badan remaja putri. Analisis statistic yang digunakan adalah korelasi bivariate pearson product moment untuk mengetahui sejauh mana hubungan indeks massa tubuh terhadap menarche. Berdasarkan penelitian ini dapat disimpulkan bahwa tidak terdapat hubungan positif antara IMT dengan usia Menarche.
\end{abstract}

Kata Kunci : Menarche, IMT

\begin{abstract}
Menarche or first menstruation is one of the teenage early sign of women. Shift of age menarche to younger age, will cause girl having the impact of stress emotional, the risk of breast cancer, the risk of cardiovascular disease and hypertension. Variations during the onset of menarche are influenced by a variety of factors, one is weight. In this study weight measured using the parameters of the body mass index (BMI). The aim of this research is to determine the relationship body mass index (BMI) with age menarche.This research is analytic correlation with the design of the study of cross-sectional. Techniques sample used is the total sample as much as 34 student. Implemented is September to November 2018 in junior Muhammadiyah I Ternate city. Research data obtained by questioner and direct measurement of the weight and height. Statistical analysis used is correlation bivariate Pearson product moment (research results) the result of analysis on person correlation or correlation product of the moment
\end{abstract}


HUBUNGAN INDEKS MASSA TUBUH (IMT) DENGAN USIA MENARCHE PADA REMAJA PUTRI DI SMP MUHAMMADIYAH I KOTA TERNATE TAHUN 2018

shows -0,288, the value of $P$ is 0,099> from the value of (0,05). From the analysis, it describes that the value of correlation is very weak or almost no relationship, Based on this study, it can be concluded that there is no positive relationship between the BMI with age menarche

Keywords : Menarche, BMI

(C) 2017 Poltekkes Kemenkes Ternate

\footnotetext{
Alamat korespondensi:

Poltekkes Kemenkes Ternate, Ternate - West Maluku Utara, Indonesia

Email: uppmpoltekkesternate@gmail.co.id
}

ISSN 2597-7520

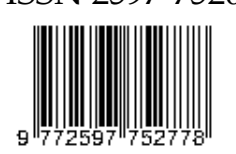




\section{HUBUNGAN INDEKS MASSA TUBUH (IMT) DENGAN USIA MENARCHE PADA REMAJA PUTRI DI SMP MUHAMMADIYAH I KOTA TERNATE TAHUN 2018}

\section{PENDAHULUAN}

Dalam perkembangan siklus hidup manusia, masa remaja merupakan masa yang sangat penting setelah melewati masa kanakkanak untuk menuju masa dewasa yang terjadi antara usia 10-19 tahun. Sebelum memasuki masa remaja, seseorang akan mengalami periode pubertas terlebih dahulu. Pada periode pubertas inilah akan terjadi percepatan pertumbuhan dan perkembangan fisik dari anak-anak menjadi dewasa serta mengalami kematangan organ reproduksi seksual. Masa pubertas pada wanita ditandai oleh pertumbuhan fisik yang cepat, menarche, perubahan psikologis dan timbulnya ciri-ciri kelamin sekunder. (Manuaba,2009)

Menarche merupakan menstruasi yang pertama kali dialami wanita, dimana secara fisik ditandai dengan keluarnya darah dari vagina akibat peluruhan lapisan endometrium. Menarche terjadi pada periode pertengahan pubertas atau yang biasa terjadi 6 bulan setelah mencapai puncak percepatan pertumbuhan. Usia menarche bervariasi dari rentang umur 10-16 tahun, akan tetapi usia menarche dapat dikatakan normal apabila terjadi pada usia 12-14 tahun. Membaiknya standar kehidupan berdampak pada penurunan usia menarche ke usia yang lebih muda (menarche dini). Kondisi menarche dini ini dikaitkan dengan pubertas prekoks yang terjadi pada anak di usia kurang dari 12 tahun. (Susanti, 2012)

Prevalensi menarche dini yang cukup tinggi ditemukan di SMP Muhammadiyah I Kota Ternate. Hal ini dibuktikan dari hasil skrining awal yang menunjukkan bahwa $69 \%$ dari total 49 siswi kelas VII telah mengalami menstruasi pertama dibawah usia 12 tahun. SMP yang masuk dalam Wilayah Binaan Kesehatan Reproduksi Jurusan Kebidanan Poltekkes Kemenkes Ternate ini, dipilih sebagai tempat pengambilan sampel. Karakteristik pada sampel tersebut digunakan untuk mewakili kejadian menarche dini pada seluruh populasi di SMP Muhammadiyah I Kota Ternate.

Pergeseran usia menarche ke usia yang lebih muda, akan menyebabkan remaja putri mengalami dampak stress emosional. Beberapa penelitian juga menyebutkan bahwa usia menarche di bawah 12 tahun berhubungan dengan risiko terkena kanker payudara, obesitas abdominal, resistensi insulin, penumpukan lemak dalam jaringan adiposa, risiko penyakit kardiovaskular dan hipertensi. Keanekaragaman konsumsi makanan dan faktor genetik merupakan indikator utama timbulnya menarche dini terutama sebagai pemicu keluarnya Gonadotropin Releazing Hormone (GnRH). Menarche yang merupakan salah satu perkembangan reproduksi juga dipengaruhi status gizi. Penilaian status gizi dapat dilakukan dengan menghitung IMT (Indeks Massa Tubuh) dengan membandingkan berat badan $(\mathrm{kg})$ dengan kuadrat tinggi badan $(\mathrm{m} 2)$ yang membedakan status gizi kurus, normal dan gemuk. Berdasarkan hal tersebut di atas penelitian ini bertujuan untuk mengetahui hubungan antara Indeks Massa Tubuh (IMT) dengan usia Menarche pada remaja Putri di SMP Muhammadiyah I Kota Ternate

\section{METODE}

Penelitian ini menggunakan jenis penelitian Analitik korelasi dengan desain studi cross sectional yaitu untuk mengetahui hubungan indeks massa tubuh (IMT) dengan usia menarche pada siswi SMP Muhammadiyah 1 Kota Ternate Tahun 2018. Kriteria inklusi penelitian ini yaitu siswi yang telah mengalami menarche (menstruasi pertama) dalam waktu maksimal 6 bulan sebelum pengambilan data dan hadir saat pengumpulan data dilakukan, sedangkan kriteria eksklusi yaitu siswi yang tidak bersedia menjadi sampel dan mengalami gangguan komunikasi. Pengambilan sampel dalam penelitian ini dilakukan dengan teknik total sampling. Metode pengumpulan data melalui wawancara menggunakan kuesioner yang dibuat oleh peneliti. Kuesioner yang akan diisi atau ditanya langsung kepada responden yaitu untuk mengetahui usia responden dan menarche responden. Kemudian peneliti menggunakan timbangan berat badan dan pengukur tinggi badan untuk mengetahui indeks masa tubuh responden dengan menggunakan rumus berdasarkan Studi literature yang ada.

Analisis univariat digunakan untuk mendeskripsikan karakteristik masingmasing responden, yakin dengan melihat nilai mean, median nilai minimum dan maksimum dan variabel yang diteliti 


\section{HUBUNGAN INDEKS MASSA TUBUH (IMT) DENGAN USIA MENARCHE PADA REMAJA PUTRI DI SMP MUHAMMADIYAH I KOTA TERNATE TAHUN 2018}

meliputi : usia, tinggi badan, berat badan, IMT, menarche. Adapun analisis bivariat digunakan untuk mengetahui hubungan antara indeks masa tubuh dengan menarche. Dalam menganalisa data secara bivariat pengujian data dilakukan dengan menggunakan uji statistic korelasi bivariate pearson product moment untuk mengetahui sejauh mana hubungan indeks masa tubuh terhadap menarche dengan pedoman sebagai berikut :

Korelasi dapat bernilai positif dan negative. Korelasi bernilai positif menunjukan arah yang sama pada hubungan antara variabel. Artinya, jika variabel 1 besar maka variabel 2 semakin besar pula. Sebaliknya, korelasi bernilai negative menunjukan arah yang berlawanan artinya, jika variabel 1 besar maka variabel 2 menjadi kecil. $\alpha$ signifikasi $95 \%(\alpha=0,05)$.

\section{Hasil dan Pembahasan \\ Tabel 1 Distribusi responden berdasarkan umur menarche di SMP Muhammadiyah 1 Kota Ternate

\begin{tabular}{|c|c|c|}
\hline $\begin{array}{l}\text { Umur } \\
\text { Menarche }\end{array}$ & $\mathbf{n}$ & $\%$ \\
\hline $9-9,9$ & 1 & $\underline{3}$ \\
\hline $10-10,9$ & 5 & 14,7 \\
\hline $11-11,9$ & 22 & 64,7 \\
\hline $12-12,9$ & 6 & $\underline{17,6}$ \\
\hline Total & 34 & 100,0 \\
\hline Mean $=11,3$, & & \\
\hline
\end{tabular}

Dari table tersebut diatas, dapat dijelaskan bahwa distribusi umur responden yang lebih banyak adalah 11-11,9 tahun dengan persentasi sebesar $64,7 \%$ sedangkan mean rata-rata umur menarche adalah di usia 11,3 tahun.

Tabel 2 Distribusi Responden Berdasarkan Tinggi Badan Responden di SMP Muhammadiyah 1 Kota Ternate Tahun 2018

\begin{tabular}{c}
$\begin{array}{c}\text { Tinggi } \\
\text { Badan }\end{array}$ \\
\hline 140,00 \\
\hline 141,00 \\
\hline 143,00 \\
\hline
\end{tabular}

\begin{tabular}{|c|c|c|}
\hline 146,00 & $\underline{6}$ & 17,6 \\
\hline 147,00 & 3 & $\underline{8,8}$ \\
\hline 148,00 & 1 & $\underline{2,9}$ \\
\hline 149,00 & 4 & 11,8 \\
\hline 150,00 & $\underline{3}$ & $\underline{8,8}$ \\
\hline 153,00 & 4 & 11,8 \\
\hline 154,00 & $\underline{3}$ & $\underline{8,8}$ \\
\hline 155,00 & 2 & $\underline{5,9}$ \\
\hline 156,00 & $\underline{3}$ & $\underline{8,8}$ \\
\hline 157,00 & 2 & $\underline{5,9}$ \\
\hline Total & $\underline{34}$ & $\underline{100,0}$ \\
\hline \multicolumn{3}{|l|}{ Mean $=150$} \\
\hline St.Dev $=4,6$ & & \\
\hline
\end{tabular}

Dari tabel tersebut diatas, diperoleh data tinggi badan responden yang lebih banyak adalah $146 \mathrm{~cm}$ dengan persentasi sebesar $17.6 \%$ sedangkan mean rata-rata tinggi badan remaja adalah $150 \mathrm{~cm}$.

Tabel 3 Distribusi Responden Berdasarkan Berat Badan di SMP Muhammadiyah 1 Kota Ternate Tahun 2018

\begin{tabular}{|c|c|c|}
\hline Berat Badan & $\mathbf{n}$ & $\%$ \\
\hline $30-39,9$ & 7 & 20,6 \\
\hline $40-49,9$ & 21 & 61,7 \\
\hline $50-59,9$ & 4 & 11,7 \\
\hline $60-69,9$ & 2 & 6 \\
\hline Total & 34 & 100,0 \\
\hline
\end{tabular}

Mean $=44,45$

St.Dev $=7,0$

Dari tabel tersebut diatas, dapat dijelaskan bahwa berat badan responden yang lebih banyak adalah 40-49,9 dengan persentasi sebesar $61,7 \%$ sedangkan mean rata-rata tinggi badan remaja adalah $44,45 \mathrm{~kg}$

Tabel 4 Distribusi Responden berdasarkan kategori IMT di SMP Muhammadiyah 1 Kota Ternate Tahun 2018

\begin{tabular}{|c|c|c|}
\hline Kategori IMT & $\mathbf{N}$ & $\%$ \\
\hline$<17.0$ & 5 & 14,7 \\
\hline$>18.5-25.0$ & 23 & 67,6 \\
\hline $17.0-18.5$ & 6 & 17,6 \\
\hline Total & 34 & 100,0 \\
\hline
\end{tabular}

Tabel tersebut diatas memaparkan distribusi responden berdasarkan kategori IMT. Pengukuran ini menunjukkan data IMT/ Berat badan kurang sebanyak $14,7 \%$, Normal $67,6 \%$ dan obesitas $17,6 \%$.

Jurnal Kesehatan Published By Poltekkes Ternate, 12 (2), 2019, Pages 192 - 198 


\section{HUBUNGAN INDEKS MASSA TUBUH (IMT) DENGAN USIA MENARCHE PADA REMAJA PUTRI DI SMP MUHAMMADIYAH I KOTA TERNATE TAHUN 2018}

Tabel 5 Distribusi Responden berdasarkan nilai korelasi antara umur menarche dengan IMT di SMP Muhammadiyah 1 Kota Ternate Tahun 2018

\begin{tabular}{llcc}
\hline & \multicolumn{1}{c}{ Umur } & \multicolumn{1}{c}{$\begin{array}{c}\text { Manarche } \\
\text { Man }\end{array}$} & IMT \\
\hline $\begin{array}{l}\text { Umur } \\
\text { Menarc } \\
\text { he }\end{array}$ & $\begin{array}{l}\text { Pearson } \\
\text { Correlation }\end{array}$ & $\mathbf{1}$ & $\mathbf{- 0 , 2 8 8 ~ d}$ \\
\cline { 2 - 4 } & $\begin{array}{l}\text { Sig. (2-tailed) } \\
\text { N }\end{array}$ & 34 & 0,099 \\
\cline { 2 - 4 } IMT & $\begin{array}{l}\text { Pearson } \\
\text { Correlation }\end{array}$ & $\mathbf{- 0 , 2 8 8}$ & $\mathbf{1}$ \\
\cline { 2 - 4 } & Sig. (2-tailed) & 0,099 & \\
\cline { 2 - 4 } & $\mathrm{N}$ & 34 & 34 \\
\hline
\end{tabular}

Berdasarkan tabel 5 tersebut menunjukan bahwa nilai person corelation atau corelation product of moment adalah 0,288 . Hal tersebut menunjukan bahwa nilai korelasi antara umur menarche dengan IMT sangat lemah atau hampir tidak ada hubungan. Hal ini juga dapat dilihat dari nilai p yaitu $0.099>$ dari nilai $\alpha(0.05)$, berarti dalam hal ini $H_{o}$ diterima dan menolak $H_{a}$.

Berdasarkan literature-literatur yang ada, banyak faktor yang mempengaruhi status menarche remaja putri diantaranya status gizi, genetik (usia menarche ibu), keterpaparan media massa orang dewasa, aktivitas olahraga, sosial ekonomi orang tua, factor psikologis (rangsangan psikis), adat kebiasaan, ada tidaknya penyakit yang diderita, dan lain-lain (Ecstasiana, 2008). Akan tetapi, karena keterbatasan yang dimiliki peniliti maka penelitian ini hanya meneliti variable status menarche siswi dan status gizi saja seperti yang terdapat pada kerangka konsep pada bab 3. Peniadaan variable faktor psikologis (rangsangan psikis) karna responden belum terlihat dewasa untuk di tanyakan mengenai rangsangan psikis, variable adat istiadat tidak dimasukan karna responden dianggap homogen karna tinggal disuatu daerah yang sama, sedangkan variable penyakit yang diderita tidak dimasukkan kedalam penelitian karena responden dianggap memiliki keadaan lahir dan batin sehat. Dengan keterbatasan penelitian ini kemungkinkan belum diperoleh gambaran keadaan yang sebenarnya.

\section{Status Menarche}

Responden adalah remaja putri yang sudah mengalami menarche sebanyak 34 siswi (100\%). Usia rata-rata menarche responden adalah $11.3 \pm 0.93$ tahun. Kejadian menarche terbanyak terdapat pada usia 11 tahun $(17.6 \%)$, dan responden dengan usia menarche termuda adalah 9.11 tahun (2.9\%) an usia tertua adalah 12.50 tahun (2.9\%).

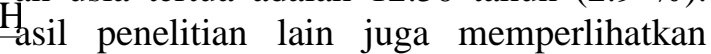
kurang lebih persamaan usia menarche, uiantaranya dalam penelitian yang di lakukan oleh Pujiani.(2012) memperlihatkan Subjek pada kelompok gizi berlebih mengalami $\mathrm{m}_{\text {enarche pada usia yang lebih muda }(11,25}$ haun) dibandingkan dengan kelompok gizi ormal (12,56 tahun) dan kurang (13,13 foun). Penelitian yang dilakukan oleh Matondang (2008) memperlihatkan bahwa $23.2 \%$ respondan sudah mengalami menarche dengan usia rata-rata menarche adalah 10 tahun 8 bulan, sedangkan penelitian yang dilakukan oleh Ecstasiana (2008) memperlihatkan bahwa 25\% responden sudah mengalami menarche dengan usia rata-rata $10.47 \pm 0.63$ tahun. berdasarkan penelitianpenelitian diatas memperlihatkan bahwa ratarata usia menarche pada remaja putri saat ini antara 10-11 tahun.

Usia terjadinya menarche di beberapa Negara di dunia memeperlihatkan kecenderungan menuju usia yang lebih muda. Penurunan rata-rata usia menarche mulai diketahui pada awal abad ke-20. Terlihat pada beberapa penelitian di negara-negara industri benua Amerika dan Eropa dengan ditemukannya penurunan usia menarche sebesar 2-3 bulan tiap dekade dalam kurun waktu 100 sampai 500 tahun terakhir. Di Amerika Serikat, rata-rata usia menarche adalah lebih dari 14 tahun sebelum tahun 1900 dan antara tahun 1988 dan 1994 menurun menjadi 12,43 tahun. Di Benua Eropa, seperti di Portugis, Italia, Spanyol, Venezuela dan Inggris, umur rata-rata menarche untuk remaja putri yang lahir di tahun 1880-1890 adalah 15,0 tahun dan menjadi 12,03 tahun untuk remaja putri yang lahir di tahun 1970-1980.

Penurunanan usia menarche saat ini diperkirakan karna beberapa factor yaitu perbaikan status gizi remaja putri di dalam keluarga, faktor genetik dan lingkungan. selain itu karena adanya keterpaparan media massa orang dewasa (elektronik/cetak) yang akan 


\section{HUBUNGAN INDEKS MASSA TUBUH (IMT) DENGAN USIA MENARCHE PADA REMAJA PUTRI DI SMP MUHAMMADIYAH I KOTA TERNATE TAHUN 2018}

mempengaruhi hormon FSH (Follicle Stimulating Hormone) yang terdapat di dalam otak kemudian bekerja sama dengan hormon estrogen sehingga akan memacu percepatan menarche pada remaja putri.

\section{Analisis Bivariat}

Hasil penelitian ini menunjukkan hubungan tidak bermakna antara status gizi dan status menarche. Berdasarkan hasil uji person corelation atau corelation product of moment adalah $-0,288$. Hal tersebut menunjukan bahwa nilai korelasi antara umur menarche dengan IMT sangat lemah atau hampir tidak ada hubungan. Hal ini juga dapat dilihat dari nilai p yaitu $0.099>$ dari nilai $\alpha(0.05)$, berarti dalam hal ini $H_{o}$ diterima dan menolak $H_{a}$. Hal ini sejalan dengan penelitian yang dilakukan oleh Ectasiana (2008), namun bertantangan dengan penelitian yang dilakukan Pujiani (2012) yang menyebutkan bahwa terdapat hubungan yang bermakna antara status gizi dengan usia menarche. oleh Ginarhayu (2008) serta penelitian yang dilakukan oleh Amaliah dan Pujonarti (2010) terhadap remaja usia 1015 tahun di Indonesia yang mengungkapkan bahwa usia menarche memiliki hubungan signifikan dengan status gizi di mana remaja dengan status gizi normal dan berlebih 1,94 kali lebih banyak mengalami menarche daripada yang berstatus gizi kurang.. Status gizi yang baik akan meningkatkan BMI pada remaja putri yang akan berdampak pada menurunnya umur menarche. Walaupun penelitian ini tidak tidak berhubungan bermakna, akan tetapi pada penelitian ini didapatkan hasil bahwa ada $67,6 \%$ responden yang berstatus gizi normal sudah mengalami menarche, jumlah ini lebih banyak dibandingkan responden yang berstatus gizi kurang yang sudah mengalami menarche yaitu $14.7 \%$. data yang ada menunjukan bahwa sebanyak 5 responden berstatus gizi kurang. Hal ini disebabkan perilaku responden yang memungkinkan besar melakukan diet oleh karena umur responden yang memasuki remaja lebih cenderung unutk menginginkan bentuk tubuh terlihat langsing walaupun berdasarkan penggukuran IMT/U berada pada status gizi normal.

\section{Penutup}

Berdasarkan hasil penelitian yang dilakukan maka dapat disimpulkan bahwa tidak terdapat hubungan positif antara IMT dengan usia Menarche pada remaja putri di SMP Muhammadiyah 1 Kota Ternate. Informasi dan edukasi secara berkesinambungan perlu diberikan kepada remaja putri mengenai kesehatan reproduksi serta pentingnya status gizi normal untuk mendukung pertumbuhan dan perkembangan reproduksi yang optimal.

\section{Daftar Pustaka}

Astuti, R., (2010). Usia Menarche, Indeks Masa Tubuh, Frekuensi Konsumsi, dan Status Sosial Ekonomi Orang Tua pada Siswa SLTP di Pinggir dan Pusat Kota, Kota Semarang. Jurnal Universitas Muhammadiyah Semarang. 9: 181-191. jurnal. unimus.

Amaliah N, Pujonarti SA.(2010) Hubungan status gizi dengan status menarche pada remaja (usia 10-15 tahun) di Indonesia tahun 2010. Jurnal Kesehatan Reproduksi 2010. Vol. 4 No 1. 1-10.

Dahlan MS. (2008) Statistik untuk Kedokteran dan Kesehatan. Jakarta: Salemba Medika,. Hal.128, 189-190.

Fajriyanti, L.A., (2008). Hubungan antara Status Gizi, Kontak Media Pornografi dengan Menarche Dini pada Pelajar Madrasah Ibtidaiyah Negeri Nanggungan Kecamatan Prambon Kabupaten Nganjuk. Skripsi. Surabaya, Universitas Airlangga. Surabaya

Kartono. (2009). Psikologi Wanita, Mengenal Gadis remaja dan wanita dewasa, Bandung: Mandar Maju

Lusiana, S.A., (2008). Satus Gizi, Konsumsi Pangan dan Usia Menarche Anak Perempuan Sekolah Dasar di Bogor. Jurnal Gizi dan Pangan. Program Studi Gizi Masyarakat dan Sumber daya Keluarga. Fakultas Pertanian. Institut Pertanian Bogor.

Manuaba, I.A. (2009). Memahami Kesehatan Reproduksi Wanita. Jakarta: EGC.

Maulidiah, F. (2011). Gambaran Status Gizi dan Genetik pada Kejadian Menarche di Perumahan Taman Pinang RW 05 Sidoarjo. STIKES YARSIS.

Macsali, F., et al.,( 2011). Early Age at Menarche, Lung Function, and Adult 
Asthma. American Journal of Respiratory and Critical Care Medicine. 183: 8-14. http: // www. atsjournals. org/ doi / full/10. 1164/rccm.200912-1886OC.

Malikhah, Anik. (2013). Hubungan status gizi dengan usia menarche pada remaja putri di SMP Negeri 01 Pringapus kabupaten Semarang. Available from : http://www.perpusnwu.web.id.

Putri, Anni Kartika. (2009). Hubungan antara status gizi, keterpaparan media cetak/elektronik, status menarche ibu(genetik) dan aktivitas olahraga terhadap status menarche pada siswi di SMP Al-Azhar Rawamangun, Jakarta Timur

Pujiani.(2012) Hubungan antara Status Gizi dengan Usia Menarche. J Kesehat Darul Ulum Jombang. 2012;1-7.

Rosenthal, M., (2009). Revolusi Terapi Hormon: Pendekatan Alami. Yogyakarta: B-First.

Riskesda. (2010). Laporan Riset Kesehatan Dasar. Badan Penelitian dan Pengembangan Kesehatan RI.

Santoso, S. (2010). Statistik Multivariat. Jakarta: Elex Media Komputindo.

Sugiyono. (2008). Metode Penelitian Bisnis. Bandung: Alfabeta.

Susanti, A.V. (2012). Faktor Risiko Kejadian Menarche Dini pada Remaja di SMPN 30 Semarang. Journal of Nutrition College. 1(1): 386-407. Universitas Diponegoro.

Salirawati D. (2010) Pengaruh Pola Konsumsi Pangan terhadap Terjadinya Menstruasi Dini dan Kesiapan Anak dalam Menghadapi Masa Pubertas. Yogyakarta (Indonesia): Universitas Negeri Yogyakarta;.

Tim Penulis Poltekkes Depkes Jakarta, (2010), Kesehatan Remaja Problem dan Solusinya. Jakarta: Salemba Medika;. hal.12-15.

Waryana. (2010). Gizi Reproduksi. Yogyakarta: Pustaka Rihama;

Winkjosastro, Hanifa (2009) Ilmu Kandungan Jakarta: Yayasan Bina Pustaka Sarwono Prawirohardjo 